\title{
Management of atopic dermatitis
}

\author{
JAMES E. RASMUSSEN \\ Department of Dermatology, The University of Michigan, Ann Arbor, U.S.A.
}

Previous articles have presented interesting and thorough discussions of the immunology of $\operatorname{IgE}$, mast cells, T-cells and the basic pharmacology of atopic dermatitis. Others have described some aspects of the treatment of atopic dermatitis by modification of diet, avoidance of inhalant allergens and psychotherapy.

This review will discuss recent advances in therapy of atopic dermatitis (AD) excluding those presented in other articles. Some of these therapies are either experimental or somewhat controversial. However, new therapies should not be tried without first having given standard therapy a long and reasonable chance to succeed. This is important because AD does not last forever and many patients with a milder disease will heal spontaneously.

\section{Atopic dermatitis}

Rajka (1) believes that most cases of infantile atopic dermatitis heal at 2-3 years of age. $\mathrm{Pa}-$ tients with widespread severe involvement and those who persist past 6 years have a much worse prognosis. Roth \& Kierland (2) conducted a 20-year follow-up on approximately 200 adult patients. Forty percent of those with mild AD had cleared but only $29 \%$ of those affected with severe $\mathrm{AD}$ were similarly improved.

\section{Standard therapy}

Standard therapy should be directed toward controlling the dryness, erythema and pruritus that characterize patients of all ages with AD. I believe that to ensure compliance, standard therapy should be simple and consist of only three or four basic items. I insist that patients comply completely with these directions before venturing into more difficult therapy. My standard therapy includes mild to moderate corticosteroids ( $1 \%$ hydrocortisone or $0.025 \%$ $0.1 \%$ triamcinolone), frequent bathing, avoidance of harsh soaps, and the liberal use of light to heavy lubricants depending upon the season and the patient's tolerance. Topical steroids should never be applied more than 2-3 times a day whereas lubricants can be applied as needed for dryness. For patients whose disease is particularly severe, it is often more effective to begin with a 1-2 week course of the most potent topical corticosteroid available tapering to a low to intermediate potency corticosteroids. This often gives an immediate burst of relief which can then be maintained with more moderate drugs. Pediatricians and other non-dermatologists frequently err when giving corticosteroids that are far too mild to obtain any therapeutic benefit.

Oral antihistamines, in my experience, are remarkably ineffective for the long-term management of $\mathrm{AD}$. The initial usefulness is soon overcome by rapid tolerance and I use them primarily as sedatives at bedtime.

This is all that I try to accomplish at the first visit. Giving patients complex instructions for modification of diet, pet control, means to increase the household humidity, avoidance of inhalants, avoidance of woolens and major changes in bathing habits are usually too overwhelming and confusing to be attempted on the first visit.

It is much better to insist on compliance with basic therapy before switching to more advanced therapy. Lichenified areas are much more difficult to treat. 


\section{Advanced therapy}

Many articles have already discussed most other aspects of advanced therapy. I will describe recent advances in the use of ultraviolet light, degerming the infected skin, use of oil of evening primrose and EPA, cyclosporine, chloroquin, phosphodiesterase inhibitors and avoidance of the house dust mite.

\section{Advanced therapy 1 - systemic steroids}

If the patient does not respond to outpatient therapy with mild topical steroids, lubricants and antihistamines, and if the disease appears inflammatory as opposed to lichenified, I next consider a short course of oral corticosteroids (prednisone $1 \mathrm{mg} / \mathrm{Kg}$ ) for 7-21 days. This drug is far too toxic to be used on a long-term daily basis except to those with life-threatening eczema and asthma.

Recently, Atherton's group (3) proposed a novel method of combining inhaled beclomethasone diproprionate plus the same agent given orally. In a placebo controlled trial, 26 children with severe atopic eczema responded significantly better while receiving active agent than placebo. Skin involvement improved by about a half and there was a parallel reduction in itch. They obtained evidence of only very mild adrenal suppression but also believed the drug may be working at the local level of the gut to decrease gastrointestinal permeability to antigens.

\section{Advanced therapy 2 - UV light}

If topical and systemic corticosteroids along with lubricants and antihistamines do not produce a satisfactory response, then the patient should be admitted to the hospital for a course of ultraviolet light. Falk (4) evaluated $106 \mathrm{pa}$ tients with $\mathrm{AD}$ who were given either ultraviolet $\mathrm{B}$ (UVB) or a combination of $\mathrm{A}$ and $\mathrm{B}$ (UVAB). In group UVAB, $94 \%$ of the 54 patients were in remission after 18 treatments compared to only $84 \%$ of 52 patients in group B after 23 treatments. This difference was statistically significant $(P<0.01)$. Of those responding well to therapy, 30 of 44 in UVB relapsed within 3 months after the last treatment compared to only 27 of 51 in group UVAB.

Very similar results in a smaller group of patients were obtained by Midelfart, Stenvold \& Volden (5). Fifty-six patients with severe AD were treated with UVB alone (33 patients) or a combination of UVB and UVA (23 patients). Forty-eight percent of UVAB-treated patients achieved complete remission compared to $27 \%$ of those treated with UVB alone.

Atherton et al. (6) treated 15 adolescent children having severe eczema with psoralen chemotherapy (PUVA). They used psoralen at a dose of $0.6 \mathrm{mg} / \mathrm{Kg}$ body weight with treatment administered either two or three times a week. Patients were treated with one $\mathrm{J} / \mathrm{cm}^{2}$ with the UVA dose gradually increasing by increments of $0.5-2.0 \mathrm{~J} / \mathrm{cm}^{2}$ at intervals of not less than 1 week depending upon skin tolerance and response until clearly cured. Fourteen of the 15 patients achieved near clearance which took from 10-25 weeks (medium 16 weeks). Remission was induced in 9 children.

Of the 7 children with adequate data, 6 had growth velocities below the third percentile. During and after PUVA treatment, all 6 of these children achieved growth velocities between the 50th and 97 th percentile.

\section{Advanced therapy 3 - role of infection}

Acute or flaring $\mathrm{AD}$ is frequently considered to have an infectious component. Numerous studies have shown that the skin of children with atopic dermatitis is heavily colonized with coagulase positive Staphylcoccus aureus. Leyden, Marples \& Kligman (7) showed that both the involved and uninvolved skin of patients with atopic dermatitis were heavily colonized with coagulase-positive Staphylcoccus aureus. Wet lesions of atopic dermatitis carry a tremendous burden of organisms with lesser amounts being found in the dry, lichenified areas and smaller 
quantities present in clinically normal skin. The exact role of these organisms in the etiology of atopic dermatitis is not known for certain but they may play both an infectious and an allergic role.

David and Cambridge (8) followed 190 children with atopic dermatitis prospectively for 2 $1 / 2$ years. Seventy-six children $(40 \%)$ had exacerbations of their eczema due to bacterial infection and $25(15 \%)$ resulted in admission to hospital. Staphylococcus aureus was the most common recovered organism being found in $97 \%$ of patients.

Welbourn, Champion and Parish in a series of three classic papers (9-11) evaluated 122 patients with eczematous dermatitis. They showed that a high percentage had immediate or 4-h (Arthus-like) responses to intradermal skin tests with staphylococcal antigens. In addition, staphylococcal antigen was shcwn on the skin surface and in the dermis indicating percutaneous absorption. Approximately $60 \%$ of the patients had circulating anti-staphyloccocal immunoglobulin that was thought to participate in this hypersensitivity reaction.

Lever et al. (12) evaluated 49 patients with atopic dermatitis in a double-blind placebo crossover trial of mupirocin, a topical anti-staphylococcal antibiotic. All patients had heavy colonization of the skin with Staphylococcus aureus prior to therapy. The bacterial count was significantly reduced by a 2 -week treatment with topical mupirocin twice a day but not by the placebo. This was accompanied by significant reduction in clinical severity which was maintained over 4 weeks post-therapy even though recolonization occurred during this period. Despite recolonization, clinical parameters remained improved and no serious side effects were observed.

Many of the new imidazole group of antifungal agents are also potent antibacterials. White \& Blatchford (13) studied 19 patients with severe atopic eczema. They were treated with $2 \%$ miconazole plus $1 \%$ hydrocortisone cream for 14 days. Seventeen of 19 (89\%) demonstrated a significant improvement and the combination was rated as better than previous therapy by $68 \%$ of the patients.
It also is generally accepted that the oral use of systemic antibiotics is useful for acute, weeping flares of $\mathrm{AD}$, particularly those which appear to be secondarily infected. There are no long-term studies on the degree of benefits such therapy provides and the reader should always be aware of the potential for development of resistance following both topical and/or systemic therapy. Somewhat limiting the usefulness of the imidazoles and mupirocin is their relatively high cost and small package size.

\section{Advanced therapy 4 - dietary supplementation with eiocosapentenoic acid (EPA) and oil of evening primrose}

Wright \& Burton (14) were among the first to conduct a double-blind, controlled, crossover study of various doses of oral evening primrose oil. They evaluated 99 patients with atopic eczema. Sixty adults received either two, four or six capsules twice daily while 39 children (8 months - 14 years of age) received one or two capsules twice a day. Each capsule contained $360 \mathrm{mg}$ of linoleic acid and $45 \mathrm{mg}$ of gammalinolenic acid. The brand name Efamol was used throughout this study. In the low-dose groups in children and adults, no objective improvements were noticed but patients did feel that prutitus was improved compared to placebo $(P<0.05)$. In the higher dose groups, Efamol was better than placebo with regard to itch, scaling and general severity. These responses were noted most prominently in the adult groups and less so among children. Adult patients in the high-dose group noted an overall improvement in severity of about $43 \%$. No side effects were noted. The authors felt that the mode of action was uncertain but that it might involve prostaglandin synthesis and the regulation of T-lymphocytes.

A somewhat similar study was carried out by a Finish group (15). They evaluated 25 patients with atopic eczema treated with either evening primrose oil (EPO) $(n=14)$ or placebo $(n=11)$ for 12 weeks. Those patients receiving evening primrose oil noted a statistically significant reduction in the severity and grade of inflamma- 
tion as well as the percentage of body surface area involved. In addition, they felt less itch and were perceived to be less dry. EPO caused a significant rise in the amount of dihomogammalinolenic acid but plasma levels of thromboxane and prostaglandins were not changed. Other authors have not been able to duplicate these beneficial clinical results (16) and in my uncontrolled clinical experience with over 50 cases, the results have been unimpressive.

Other authors have studied the effect of dietary supplementation with eicosapentenoic acid in the treatment of atopic dermatits. Björneböe et al. (17) gave $10 \mathrm{~g}$ of fish oil (1.8 grams EPA) versus placebo (olive oil) when treating 31 adults with $\mathrm{AD}$. In a 12-week double-blind randomized trial, 16 patients were given 10 capsules max-EPA daily (1.8 grams EPA) and 15 control patients were given 10 olive oil capsules a day. Severity scores assessed by the physician showed no statistically significant difference between the active and placebo groups. However, the patient's assessment showed that max-EPA was better than placebo with regard to itch $(P<0.05)$, scale $(P<0.05)$ and total symptom score $(P<0.02)$. No significant difference was found between the groups with regard to topical steroid use during the trial.

\section{Advanced therapy 5 - phosphodiesterase inhibitors}

Hanifin et al. (18) have demonstrated that leukocytes from patients with $\mathrm{AD}$ show elevated activity of cAMP phosphodiesterase (PDE). These investigators feel that high PDE activity may allow increased IgE production and increased histamine release from basophils and mast cells. Further, they believe that this is a basic defect of atopic dermatitis.

To my knowledge there are no controlled trials of any known systemic PDE inhibitor since most of these drugs are too toxic for general use. Baer (19) advocates the use of papaverine $100 \mathrm{mg}$ 4-6 times daily and believes that it is effective in decreasing pruritus in patients with $\mathrm{AD}$. Papaverine is believed to be a non-toxic, mild vasodilator that has been in use since 1947 . Baer anecdotally noted his ther- apy of "hundreds of patients with moderately severe atopic dermatitis" and currently uses the $150 \mathrm{mg}$ time-release capsules twice (and occasionally three times) a day. He believes that it reduces itching in the majority of $\mathrm{AD}$ cases and in some patients "appears to have a truly striking effect". Baer notes that papaverine is an inhibitor of leukocyte PDE levels. Hanifin et al. (18) showed elevated PDE levels accounting for increased catabolic breakdown of cAMP which, in turn, explains the reduced cAMP unresponsiveness to histamine and isoproterenol in atopic dermatitis.

Other PDE inhibitors such as caffeine used as a $30 \%$ cream with $0.5 \%$ hydrocortisone has been reported to be more effective than $0.5 \%$ hydrocortisone alone in patients with AD (20). (Also, see article in this supplement by Hanifin (pp. 41) on the experimental drug RO201724). I have found the use of papaverine to be without substantial effect in an uncontrolled series of 50 children with atopic eczema. I have also found $30 \%$ caffeine creme to be without effect in significant atopic eczema.

\section{Advanced therapy 6 - house dust mite allergy}

Seventy-five percent of children with $\mathrm{AD}$ are sensitized to the house dust mite by the age of 10. Beck \& Hagdrup (21) analyzed 210 patients with atopic dermatitis and a positive prick test toward the house dust mite (Dermatophagoides pteronyssinus) finding a higher prevalence of a birth in the interval May to November when compared with the expected distribution. Exposure to the house dust mite is much more common during these months.

Vickers (22) noted that cell-mediated immunity to house dust mite (HDM) antigen was demonstrated in 11 of 16 patients with atopic eczema compared to 2 of 14 controls. He reviewed work showing the difficulty in hyposensitizing patients to mite antigen, and emphasized his work with avoidance of mite dust antigen using natamycin (Tymosil). This agent kills Aspergillus fungi which is the staple food of the house mite. Vickers believes house dust mite eczema is related to early morning flares, 
high IgE levels and the $4+$ positive RAST test to house dust mite. It may also be associated with a respiratory allergy. He treated 11 children in an open study in which natamycin was used throughout the house for a 6-mo period. Three children showed no change, 3 had a moderate improvement and the remaining 5 $(45 \%)$ had a dramatic improvement in both their skin and respiratory allergies.

Norris et al. (23) showed that house dust mite could play a role in the pathogenesis of atopic eczema. Application of house dust mite solution or control to the anticubital or popliteal fossae showed a marked delayed local reaction in onethird of patients with $\mathrm{AD}$ to house dust mite only. Further evidence supporting the role of HDM in the evolution of AD is the fact that HDM-specific IgE mirrors disease severity and several uncontrolled studies showing that HDM avoidance improves $\mathrm{AD}$.

\section{Advanced therapy 7 - desperation therapy}

For patients whose eczema is unresponsive to topical and intermittent use of oral corticosteroids, ultraviolet light and dietary supplements, systemic cytotoxic agents may be useful. Morrison \& Schulz (24) treated 9 patients with intractable severe atopic dermatitis. Cyclophosphamide was used in a daily dose of $100 \mathrm{mg}$ and azathioprine was administered in a dose of 50-100 mg daily. Patients were monitored carefully for development of leukopenia and thrombocytopenia. Eight patients were treated with cyclophosphamide and 2 patients were subsequently given azathioprine. All patients reported remarkable improvement in an average of $3 \frac{1}{4}$ mo. Percent skin involvement which before therapy had averaged $80 \%$ fell to an average of $7 \%$ involvement during therapy. After the drugs were stopped, remissions varied from 160 months (average $24 \mathrm{mo}$ ).

I have no experience with this drug in adults or children. Doring \& Kreppel (25) treated 62 patients suffering from $\mathrm{AD}$ with chloroquin 125-250 mg/day for 3-6 months. In 46 patients the therapy resulted in such significant improvement that all systemic and other topical therapy could be discontinued. Eight other patients reported substantial improvement but still used topical corticosteroids.

Hanifin's group (26) evaluated 18 AD patients who were treated with three times weekly injections of $50 \mathrm{mg}$ TP-5 or placebo. Younger patients $(<34 \mathrm{y})$ responded to TP-5 with much greater improvement in severity scores than TP-5 treated patients $>34$ y or to placebo patients of either age group $(P<0.05)$. Immunological abnormalities also reverted towards normal in those patients given TP-5.

In a similar study, Harper et al. (27) used Thymostimulin (TP-1) in a double-blind controlled study of 29 adults with severe life-long AD. Treatment consisted of two weekly injections of TP-1 $1.5 \mathrm{mg} / \mathrm{Kg}$ for 10 weeks. They noted a $20 \%$ reduction in clinical severity when TP-1 was compared to placebo. T8 lymphopenia, hyper IgE levels and high blood eosinophilia were unchanged in spite of the clinical improvement.

Finally I would like to speak about the dermatological applications of cyclosporine. Vanjoost et al. (28) were the first to note the beneficial effects of cyclosporine on severe AD. They reported 2 patients with severe drug-resistant disease were treated with $5 \mathrm{mg} / \mathrm{Kg} /$ day of $\mathrm{cy}$ closporine. Near complete remission (greater than $90 \%$ ) was observed in both cases after 4 weeks of therapy. There was no correlation between trough blood levels and degree of improvement. After discontinuation of cyclosporine, a gradual recurrence of lesions and pruritus was observed within 3 weeks.

At The University of Michigan we have treated a further 5 patients with low-dose cyclosporin and have noted similarly good responses with a minimal amount of side effects. A double-blind controlled study is now underway in our institution on low-dose cyclosporin therapy in the treatment of $\mathrm{AD}$. No pediatric patients, to my knowledge, have been treated with this drug, however.

De Prost reported on his recent study of topical cyclosporine at the Third International Symposium on Atopic Dermatitis held in Oslo, Norway. This was a 20 patient, double-blind, controlled, paired comparison of a $10 \%$ topical 
cyclosporine gel. Patients were evaluated at 14 days for pruritus, erythema, lichenification, and scale xerosis. De Prost reported that all parameters improved in a statistically significant fashion and that blood levels of cyclosporin were undetectable at topical dosing levels of $10 \mathrm{mg} / \mathrm{Kg}$.

\section{REFERENCES}

1. Rajka, G.: Atopic dermatitis. Major problems in dermatology. Ed Arthur Rook. 3, 7 (WB Saunders Co, London) 1975.

2. Roth, H. L. \& Kierland, R. R.: Natural history of atopic dermatitis. Arch Dermatol 89, 209-217, 1964.

3. Heddle, R. J., Soothil, J. F., Bulpitt, C. J. \& Atherton, D. J.: Combined oral and nasal beclomethasone diproprionate in children with atopic eczema: A randomized, controlled trial. BMJ 289, 652-654, 1984.

4. Falk, E. S.: UV-light therapies in atopic dermatitis. Photo Dermatol. 2, 241-246, 1985.

5. Midelfart, K., Stenvold, S. E. \& Voloden, G.: Combined UVB and UVA phototherapy of atopic eczema. Dermatologica. 171, 95-98, 1985.

6. Atherton, D. J., Carabott, F., Glover, M. T. \& Hawk, J. L. M.: The role of psoralen chemotherapy (PUVA) in the treatment of severe atopic eczema in adolescence. Br. J. Dermatol. 118, 791-795, 1988.

7. Leyden, J. L., Marples, R. R. \& Kligman, A. M. Staphylococcus aureus in the lesions of atopic dermatitis. Br. J. Dermatol. 90, 525-531, 1974.

8. David, T. J. \& Cambridge, G. C.: Bacterial infection and atopic eczema. Arch. Dis. Child. 61, 20-23, 1986.

9. Welbourn, E., Champion, R. H. \& Parish, W. E.: Hypersensitivity to bacteria in eczema I. Br. J. Dermatol. 94, 619-634, 1975.

10. Welbourn, E., Champion, R. H. \& Parish, W. E.: Hypersensitivity to bacteria in eczema. II. Br. J. Dermatol. 95, 285-293, 1975.

11. Welbourn, E., Champion, R. H. \& Parish, W. E.: Hypersensitivity to bacteria in eczema III. Br. J. Dermatol. 95, 379-387, 1975.

12. Lever, R., Hadley, K., Downey, D. \& Mackie, R.: Staphylococcal colonization in atopic dermatitis and the effect of topical mupirocin therapy. Br. J. Dermatol. 119, 189-198, 1988

13. White, I. \& Blatchford, N.: The treatment of secondary bacterial infection in atopic eczema with miconazole plus hydrocortisone. Br. J. Clin. Prac. 1, 215-218, 1983.

14. Wright, S. \& Burton, J. L.: Oral evening primose seed oil improved atopic eczema. Lancet II, 1120-1122, 1982.

15. Schalin-Karrila, M., Mattila, L., Jansen, C. T. \& Uotila, P.: Evening primose oil in the treatment of atopic eczema. Effects on clinical status, plasma phospholipid fatty acids and circulating blood prostaglandins. Br. J. Dermatol. 117, 11-19, 1987.

16. Guenther, L. \& Wexler, D.: Efamol and the treatment of atopic dermatitis. JAAD 14, 869, 1987.

17. Björnebö, A., Soyland, E., Björnebö, G. N. E., Rajka, G. \& Drevon, C. A.: Effect of dietary supplementation with eicosapentenoic acid in the treatment of atopic dermatitis. Br. J. Dermatol. 117, 463-469, 1987.

18. Hanifin, J. M., Butler, J. M. \& Chan, S. C.: Phosphodiesterase levels in leukocytes from patients with atopic dermatitis. JID 85, 161-164, 1985.

19. Baer, R. L.: Papaverine therapy in atopic dermatitis. JAAD 13, 806-808, 1985

20. Kaplan, H. J., Deman, L., Rosenberg, E. W. \& Feigenbaum, S.: Topical use of caffeine with hydrocortisone the treatment of atopic dermatitis. Arch. Dermatol 114, 60-62, 1978

21. Beck, H. I. \& Hagdrup, H. K.: Atopic dermatitis, house dust mite allergy and month of birth. Acta Derm. Venereal. 67, 448-451, 1987

22. Vickers, C. F. H.: House dust mite and eczema. Dermatology in Five Continents. C. E. Orfanos, R. Stadler \& H. Golinick, eds. Springer-Verlag, Berlin, 1988.

23. Norris, P. G., Schofield, O. \& Camp, R. D. R.: A study of the role of house dust mite in atopic dermatitis. Br. J. Dermatol. 118, 435-440, 1988.

24. Morrison, J. G. L. \& Schulz, E. J.: Treatment of eczema with cyclophosphamide and azathioprine. Br. J. Dermatol. 98, 203-207, 1978.

25. Doring, H. F. \& Kreppel, U. M.: Chloroquin-Therapie der atopishen Dermatitis. Z. Hautkr. 62: 1205-1213, 1987.

26. Hanifin, J. M., Cooper, K. D. \& Kang, K. I. F. I. Thymopoietion pentapeptide (TP-5) improves clinical parameters and lymphocyte subpopulations in atopic dermatitis. JAAD 8, 372-377, 1983.

27. Harper, J. I., White, I. R., Staughton, R. C. D. \& Hobbs, J. R.: Thymostimulin (TP-1) therapy for atopic eczema. Br. J. Dermatol. 119, 14, 1988.

28. Vanjoost, T., Stolz, E. \& Huele, F.: Efficacy of iow dose cyclosporine in severe atopic disease. Arch. Dermatol. 123, 166-167, 1987. 
This document is a scanned copy of a printed document. No warranty is given about the accuracy of the copy. Users should refer to the original published version of the material. 